\title{
LETTER
}

\section{Mapping the RP2 Locus for X-linked Retinitis Pigmentosa on Proximal Xp: A Genetically Defined 5-cM Critical Region and Exclusion of Candidate Genes by Physical Mapping}

\author{
Dawn L. Thiselton, ${ }^{1}$ R. Mark Hampson, ${ }^{1,2}$ Manimekelei Nayudu, ${ }^{1}$ \\ Lionel Van Maldergem, ${ }^{3}$ Mitchel L. Wolf, ${ }^{4}$ Bratin K. Saha, ${ }^{5}$ \\ Shomi S. Bhattacharya, ${ }^{1}$ and Alison J. Hardcastle ${ }^{1,6}$
}

\begin{abstract}
${ }^{1}$ Department of Molecular Genetics, Institute of Ophthalmology, London, UK; ${ }^{2}$ Rayne Institute, St. Thomas' Hospital, London, UK; ${ }^{3}$ Institut de Pathologie et de Genetique A.S.B.L., B-6280, Gerpinnes (Loverval), Belgium; ${ }^{4}$ Jewish Hospital, St. Louis, Missouri 63108; ${ }^{5}$ Winship Cancer Centre, Emory University School of Medicine, Atlanta, Georgia 30322
\end{abstract}

Genetic linkage studies have implicated at least two loci for X-linked retinitis pigmentosa (XLRP) on proximal Xp. We now report a defined genetic localization for the RP2 locus to a 5-cM interval in Xp11.3-11.23. Haplotype analysis of polymorphic markers in recombinant individuals from two XLRP families has enabled us to identify DXS8083 and DXS6616 as the new distal and proximal flanking markers for RP2. Using STS-content and YAC end-clone mapping, an $\sim 1.2 \mathrm{Mb}$ YAC contig has been established encompassing the proximal RP2 boundary and extending from TIMPI to DXS1240 in Xpll.23. Several ESTs have been positioned and ordered on this contig, one of which is novel to the region, identified by sequence data-base match to a physically mapped YAC insert terminal STS. Integration of the genetic and physical data has placed four retinally expressed genes proximal to DXS6616, and thereby excluded them from a causitive role in RP2. This work now provides a much needed focus for positional cloning approaches to isolation of the defective gene.

Retinitis pigmentosa (RP) is a group of hereditary progressive retinal degenerations characterized by night blindness, visual field impairment, and degenerative pigmentary changes in the retina. $\mathrm{RP}$ exists as autosomal dominant, autosomal recessive, and $\mathrm{X}$-linked forms and displays considerable genetic heterogeneity with at least 15 distinct loci so far assigned to human chromosomes (for review, see Dryja et al. 1995). X-linked retinitis pigmentosa (XLRP) is the most severe clinical form, accounting for $7-30 \%$ of all cases, depending on the population studied, with an incidence of $\sim 1: 20,000$ (Jay 1982; Heckenlively 1983). Male XLRP patients generally develop concentric visual field loss before the 20th year of life leading to severe visual handicap by the age

${ }^{6}$ Corresponding author.

E-MAIL ahardcas@hgmp.mrc.ac.uk; FAX 44-171-608-6863. of 40 (Bird 1975). Female carriers show variable symptoms of the disease on ophthalmological testing, with visual impairment usually beginning in middle age, although absence of ocular abnormalities does not exclude the carrier state (Arden et al. 1983).

In the absence of functional clues as to the pathophysiology of XLRP, positional cloning strategies have been adopted to isolate the defective genes. Following the first genetic linkage of an RP gene (designated RP2) to Xp11.3 in a panel of British families (Bhattacharya et al. 1984), subsequent genetic analyses have indicated the existence of at least three other XLRP loci (RP3, RP6, and $R P 15$ ) located more distally on Xp (Musarella et al. 1990; Ott et al. 1990; Teague et al. 1994; McGuire et al. 1995) and the fact that the disease in some families maps to none of these locations suggests the possibility of even more XLRP loci (Aldred et al. 1994). As evidence for RP6 is to date only statistical (Ott et al. 1990), and RP15 has been demonstrated in only one family (which is 


\section{THISELION ET AL.}

reported as a cone-rod degeneration; McGuire et al. 1995), the majority of XLRP families fall into the categories of $R P 2$ or $R P 3$.

The ability to distinguish between $R P 2$ and $R P 3$ is dependent on the detection of crossovers dissecting the target region by genetic linkage/ haplotype analysis, attributable to the lack of reliable clinical differences between the two disease entities (Wright et al. 1991). The clustering of XLRP genes on proximal Xp makes such genetic distinction of XLRP families difficult; however, from cumulative genetic data it appears that $R P 3$ predominates in British and American families (Musarella et al. 1990; Ott et al. 1990; Teague et al. 1994).

Precise localization of the RP3 gene to Xp21.1 by genetic linkage analysis has been augmented by the molecular genetic analysis of RP3 patients with submicroscopic DNA deletions, confining $R P 3$ to a $530-\mathrm{kb}$ stretch of DNA flanked by genetic markers OTC and DXS1110 (Roux et al. 1994). The focusing of efforts afforded by the identification of M.O., a male RP patient harboring a $75-\mathrm{kb}$ deletion within the RP3 critical region, has recently led to the isolation of a gene $(R P G R)$ in which mutations account for XLRP in a proportion of $R P 3$ patients (Meindl et al. 1996).

The $R P 2$ gene has remained broadly localized to an $~ 13-\mathrm{cm}$ interval in Xp11.22-11.3 flanked by DXS7 and DXS255, owing to a lack of recombination events in the critical region (Friedrich et al. 1992; Wright et al. 1991) and no detectable disease-associated deletions. Various multipoint and heterogeneity analyses further suggest different locations for the $R P 2$ gene within this interval (Xp11.23; Teague et al. 1994; Xp11.22; Bergen et al. 1995). Narrowing of the RP2 region will improve reliability of carrier detection and may facilitate characterization of the gene and its mutations and help resolve the issue of clinical and genetic heterogeneity.

We present here two XLRP families in which the gene responsible is consistent with an RP2 location, and where key recombinants have been identified that define both the proximal and distal boundaries of the $R P 2$ critical interval within each family. Integration of the genetic and physical maps of the region has led to the exclusion of several retinally expressed candidate genes located in Xp11.23, and the degree of refinement now renders the construction of a physical contig spanning the RP2 critical region, and isolation of candidate transcripts therein, a more manageable task.

\section{RESULTS}

\section{Haplotype Analysis}

Key recombination events within families NRP and F72 are shown in Figure 1. No deletions were detected using the 19 microsatellites listed.

\section{Family NRP}

In family NRP (Fig. 1a) individual V-1, an affected male, is a recombinant with respect to his carrier mother IV-1 between markers $M A O B$ and DXS1055. The phase of the maternal alleles was established firmly from analysis of two obligate carrier sibs (IV-2 and IV-3) who share the mother's affected haplotype. This crossover defines the distal boundary of the XLRP interval, with the disease-associated haplotype located proximal to $M A O B$, providing firm evidence for $R P 2$ segregating in family NRP. A similar crossover is seen in individual III-4, a carrier female who has inherited her mother's affected chromosome proximal to $M A O B$ and passed this recombinant chromosome onto her affected son IV-7. The phase of the alleles in II- 2 could be clearly deduced from the haplotypes of her affected sons III-3 and III-6, assuming crossover minimization.

The proximal boundary of the $R P 2$ interval is defined by an inferred crossover in individual IV-4 between markers DXS1055 and DXS6616, which has been transmitted to her affected son $\mathrm{V}-3$. It is assumed that this recombination event occurred in individual III-2, as individual IV-5 has the same affected haplotype as her maternal uncle III-1 (as seen in his daughters IV-1, IV-2, and IV-3). The disease-associated haplotype in individuals IV-4 and V-3 is therefore located distal to DXS6616. A crossover event in individual III-5 provides additional support for the location of the XLRP gene in this family. This affected male is a recombinant with respect to his carrier mother II-2 between markers DXS6616 and DXS6941, with the disease-associated haplotype located distal to DXS6941.

In summary, key recombination events in family NRP are consistent with RP2 segregation, and indicate an $R P 2$ critical region flanked by $M A O B$ (Xp11.3) and DXS6616 (Xp11.23).

\section{Family F72}

In family F72 (Fig. 1b) individual II-5 is a recombinant with respect to his carrier mother I-1 between markers DXS8083 and DXS1003. The phase of the maternal alleles was deduced from 
A

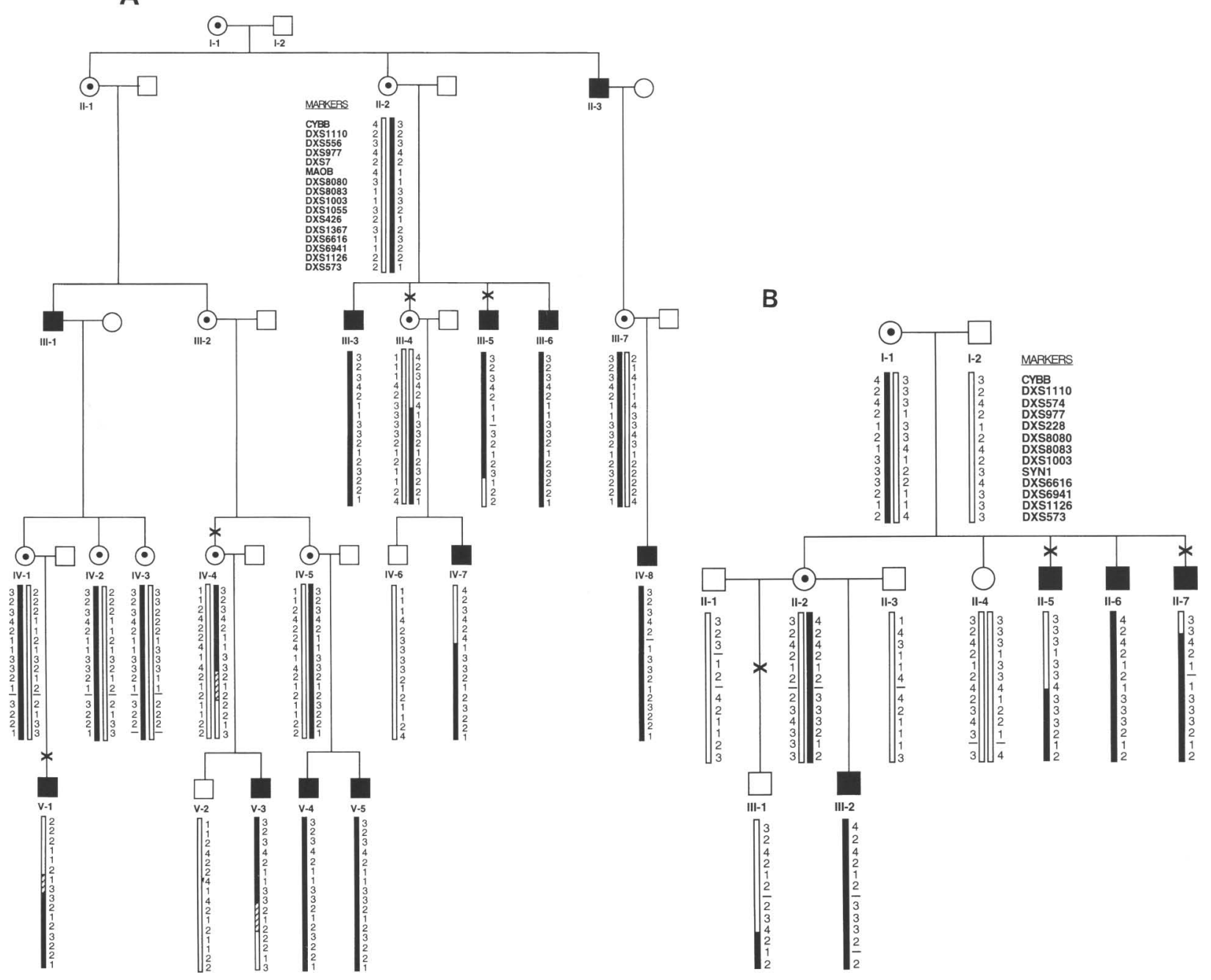

Figure 1 Pedigrees of the XLRP families used in this study, showing haplotypes constructed with the markers listed. Solid bars indicate those alleles that are linked to the XLRP mutation (i.e., disease-associated haplotype). In the case of recombinant individuals (marked by an X) the solid bar is used to depict only those alleles that can be unambiguously linked to the parental "affected" haplotype. Hatched lines represent markers that were uninformative. (A) Family NRP, with recombinant individuals IV-7, V-1, and V-3 localizing the $R P 2$ gene to the region between markers MAOB and DXS6616. (B) Family F72, with recombinant individuals II-5 and III-1 positioning the RP2 gene between markers DXS8083 and DXS6941.

the haplotypes of her phase-known unaffected and obligate carrier daughters. The diseaseassociated haplotype in affected male II-5 is located proximal to DXS8083, confirming the segregation of $R P 2$ in this family, and providing a new distal flanking marker for the $R P 2$ critical region.

A recombination event in individual III-1, an unaffected male, defines the proximal boundary of the RP2 interval in family F72. A crossover has occurred between markers DXS6616 and DXS6941, positioning the disease-containing interval distal to DXS6941. The phase of the mater- nal alleles was firmly established from analysis of the grandparental genotypes.

The crossover data clearly defines F72 as an RP2 family, with the disease gene critical interval flanked distally by DXS8083 (Xp11.3-11.23) and proximally by DXS6941 (Xp11.23).

\section{YAC Contig Construction; Generation and Physical Ordering of Sequence-tagged Sites in Xpll.23}

Sequence-tagged site (STS)-content mapping of yeast artificial chromosomes (YACs) identified 


\section{THISELTON EI AL.}

using markers from Xp11.23 established a contig spanning $1.2-\mathrm{Mb}$ (based on the additive size of minimal tiling path YACs) from TIMP1 to DXS1240 (Fig. 2). YACs were initially isolated from the library by PCR screening using markers DXS426, ZNF81, MG61, DXS722, and GATA1. STSs were derived from the left and/or right ends of the human DNA inserts in several YACs (detailed in Table 1) and proved instrumental in confirming YAC overlaps and integrity. Of the 10 total YAC insert terminals isolated, two proved to derive from regions other than $\mathrm{Xp} 11.23$ on somatic cell hybrid analysis; 34AC5LA maps to distal Xp and C01160LA maps to chromosome 6, indicating that these YACs are chimeric. FASTA data-base identity searches detected matches for two YAC insert terminals with gene sequences: 4HG2LA lies within exon 2 of the SYN1 gene, anchoring this end of the YAC firmly in Xp11.23, whereas 34AC5RA showed $99.5 \%$ identity over $210 \mathrm{bp}$ to a human infant brain cDNA [Integrated Molecular Analysis of Genomes and their Expression (IMAGE) Consortium; expressed sequence tag (EST) accession no. H09726] or 99\% identity over 209 bp to a human placental cDNA (IMAGE Consortium; EST accession no. N41839) for forward and reverse strands, respectively. This result suggests that these cDNAs are identical, and maps a new EST (expressed in brain and placenta) to the physical map of Xp11.23 (Fig. 2).

The contig comprises 18 YACs and encompasses 30 markers including 11 microsatellites, 10 gene/ESTs and eight new STSs derived from YAC insert terminals, to give a STS density of $\sim 1$ every 40 kb. Key markers (e.g., F0701LA, DXS6849, and DXS6950) and two YACs, ICRFy900C1022 (SYN1) and ICRFy900C01160 $(2 b C 6)$, have been included to allow integration with other partial YAC contigs already existing for Xp11.23 (Coleman et al. 1994; Hagemann et al. 1994; Knight et al. 1994; Fisher et al. 1995; Kwan et al. 1995), which reflect the interest in this gene-rich region of $\mathrm{Xp}$, to which many genetic diseases have been mapped (Nelson et al. 1995). The depth of the contig permitted physical ordering of most STSs/ESTs assigned to the contig, as shown in Figure 2. The order so derived is as follows: Xpter-SYN1(CA) $-T I M P 1-$ C1022RA-4HG2RA-PFC( C A ) ${ }_{n}-33$ CA 11 L A (DXS426, FO $701 \mathrm{LA}$ ) $4 \mathrm{HG} 2 \mathrm{LA}-(\mathrm{DXS} 1367$, ELK 1$)-33$ C A $11 \mathrm{R} \mathrm{A-}$ ( ZNF81, D X S6849, DXS1004E)-DXS6616DXS6950-34AC 5 RA$30 \mathrm{DH} 10 \mathrm{RA}-(M G 61$, D X S6941) - MG81( DX S $722, M G 21$ ) (DX S $1011 \mathrm{E}, M G 44$ )C $01160 \mathrm{RA}-G A T A 1$ D X S $1126-\mathrm{D}$ X S $1240-$ Xcen. Interestingly, our lo- 
Table 1. Details of Gene-based and YAC Insert STSs Derived in This Study

\begin{tabular}{|c|c|c|c|c|c|}
\hline STS name & Source & PCR primers $\left(5^{\prime}-3^{\prime}\right)$ & $\begin{array}{l}\mathrm{T}_{\mathrm{a}} \\
\left({ }^{\circ} \mathrm{C}\right)\end{array}$ & $\begin{array}{l}\text { Product } \\
\text { size (bp) }\end{array}$ & $\begin{array}{l}\text { Accession } \\
\text { no. }\end{array}$ \\
\hline GATA1 & Gene 3'UTR & $\begin{array}{l}\text { ACAGAGCATGGCCTCCAGAG } \\
\text { AGCTITGAAGGTTCAAGCCAGG }\end{array}$ & 62 & 112 & DXS9855E \\
\hline MG21 & Gene 3'UTR & $\begin{array}{l}\text { ATTATTGTCTGCGCTGACCCAGTCA } \\
\text { CTGCGTCCGAAACTGTGGAAACGTT }\end{array}$ & 62 & 323 & DXS9867E \\
\hline MG44 & Gene 3'UTR & $\begin{array}{l}\text { TGAGGCTGGTTICTGCTCGTGCTTA } \\
\text { TAGATCTTGGTTCCAGCTCTGAGTG }\end{array}$ & 62 & 494 & DXS9868E \\
\hline MG61 & Gene 3'UTR & $\begin{array}{l}\text { ATCTGTGGACCCTCATAACCCTCTT } \\
\text { GGATCTCCССTTCTCGTTTCCCCAA }\end{array}$ & 62 & 252 & DXS9869E \\
\hline MG81 & Gene 3'UTR & $\begin{array}{l}\text { ATCTCCATTCTTTGCCATGAGGG } \\
\text { AAGCAGAGCTCCACATACTTAGG }\end{array}$ & 62 & 123 & DXS9870E \\
\hline C1022RA & YAC end & $\begin{array}{l}\text { ATTAATACCGACCAGGCATGGTG } \\
\text { AGACAGGGTCTTGCTGTGTTGC }\end{array}$ & 64 & 125 & DXS9875 \\
\hline $4 \mathrm{HG} 2 \mathrm{LA}$ & YAC end & $\begin{array}{l}\text { CTTGAAAGGAACCAAGCAAGC } \\
\text { TGTGCCTGTGGTGATTAGCC }\end{array}$ & 57 & 162 & DXS9872 \\
\hline $\begin{array}{l}\text { 4HG2RA } \\
\text { (SYN1 exon2) }\end{array}$ & $\begin{array}{l}\text { YAC end } \\
\text { (EST) }\end{array}$ & $\begin{array}{l}\text { TGGCCACTCAGTTTGCAGTATG } \\
\text { CCTCTCCAGGGCAAAATACTTC }\end{array}$ & 63 & 125 & DXS9873E \\
\hline $33 \mathrm{CA} 11 \mathrm{LA}$ & YAC end & $\begin{array}{l}\text { ACTACGGAATTCCCACTT } \\
\text { AАCTTACTTGGTCTCTTG }\end{array}$ & 45 & 111 & DXS9876 \\
\hline 33CA11RA & YAC end & $\begin{array}{l}\text { GAATTCCAGCTGAGAAATGC } \\
\text { AGGCTCGGTCTCAAATGCCT }\end{array}$ & 56 & 134 & DXS9877 \\
\hline 34AC5RA & $\begin{array}{l}\text { YAC end } \\
\text { (EST) }\end{array}$ & $\begin{array}{l}\text { TACACTGTGATTTGTTGCCAGC } \\
\text { AGGAGTGTCCTGATTATGTCC }\end{array}$ & 64 & 177 & DXS9853E \\
\hline 30DH10RA & YAC end & $\begin{array}{l}\text { AGGTATACTTGCACAGACACC } \\
\text { TCAGGACTGGGGTGCCATGAC }\end{array}$ & 64 & 129 & DXS9854 \\
\hline C01160RA & YAC end & $\begin{array}{l}\text { ACACTGAGAGGCAATACTGG } \\
\text { TGGCCATTGGATGCTTCCTG }\end{array}$ & 58 & 172 & DXS9874 \\
\hline
\end{tabular}

calization of DXS1004E (ZNF41) differs from that in published reports (Knight et al. 1994; Carrel et al. 1996). In contrast to the report of Knight et al. (1994), repeated testing in our laboratory has confirmed YAC ICRFy900C1022 to be positive for DXS1004E. The additional presence of DXS1004E in ICI YACs 3EB3, 24GH5 and 31AG10 which overlap C1022, positions ZNF41 proximal to ELK1, and distal to DXS6616.

The physical ordering and orientation of the retinal cDNAs MG21, MG44, MG61, and MG81 on our contig is in agreement with that depicted on the recently published physical map of Boycott et al. (1996). Although orders could not be established between all pairs of markers, our physical mapping data demonstrates clearly that
DXS6616, the new proximal flanking marker for $R P 2$, lies distal to retinally expressed genes $M G 21$, MG44, MG61, and MG81.

\section{DISCUSSION}

XLRP is a progressive degenerative disease of the retina that is clinically and genetically heterogeneous. In this study we performed haplotype analysis in two XLRP families with 20 polymorphic microsatellite markers spanning the critical region for the most prevalent forms $R P 3$ and $R P 2$ (Xp21.1-Xp11.22). Analysis of newly positioned markers in recombinant individuals from these families has enabled us to define new proximal and distal boundaries for the RP2 gene critical 


\section{THISELTON ET AL.}

interval and reduce significantly its size. The new flanking markers in family NRP are $M A O B$ (Xp11.3) and DXS6616 (Xp11.23), whereas those in family F72 are DXS8083 (Xp11.3-11.23) and DXS6941 (Xp11.23). Taken together, assuming the defective gene is the same in both families, this data suggests a refined $R P 2$ interval flanked by DXS8083 and DXS6616 on proximal Xp, spanning $\sim 4-5 \mathrm{~cm}$. Positional cloning efforts can now be directed at this greatly reduced interval, facilitating the search for an $R P 2$ candidate gene. In the event that these two families are segregating different loci, microheterogeneity within this interval may only become evident once the disease gene for one of these families has been cloned.

Genetic heterogeneity is evident in many inherited retinal degenerations, reflecting the eye's limited repertoire of responses to a variety of genetic lesions. Another emerging pattern in ophthalmic genetics is that of "gene sharing" (allelism) in which different mutations within the same gene can cause clinically distinct ocular diseases. Two forms of autosomal congenital stationary night blindness (CSNB) have been shown to be allelic to RP: Both CSNB and RP can result from mutations in (1) the rhodopsin gene (Dryja et al. 1993; Rao et al. 1994); and (2) the gene encoding the $\beta$-subunit of the rod cGMP phosphodiesterase (Gal et al. 1994). The refinement of the $R P 2$ critical interval described here may have significant implications for the localization of other inherited X-linked retinal disorders that have overlapping map locations in Xp11.3$\mathrm{Xp} 11.22$ and which may be allelic to RP2 that is, CSNBX (Aldred et al. 1992; Bech-Hansen et al. 1992; Berger et al. 1995) and X-linked progressive cone dystrophy (Hong et al. 1994; Meire et al. 1994).

The identification of DXS6616 as the new proximal flanking marker for $R P 2$ has also enabled us to exclude several genes as potential candidates for this disorder. Four retinally expressed genes have been mapped to the OATL1 region in Xp11.23 by direct selection using an OATL1 YAC to screen a retinal cDNA library (Geraghty et al. 1993). We have positioned and ordered these genes with respect to DXS6616 on a 1.2-Mb YAC contig spanning the RP2 proximal boundary and show that DXS6616 lies distal to this cluster of retinally expressed genes, thereby excluding them from involvement in RP2. With an STS density of $\sim 1$ every $40 \mathrm{~kb}$, including seven novel STSs and a newly mapped EST, this contig signifi- cantly adds to the available maps of Xp11.23. Furthermore, the contig presented here is comprised primarily of YACs from the ICI 4X library (Anand et al. 1990), 15 of which have not previously been reported, and therefore provides a useful, alternative resource for more detailed analysis of this region of Xp11.23, well noted for its region-specific instability in YACs (Chand et al. 1995; Fisher et al. 1995; Boycott et al. 1996).

The refined RP2 interval is known to be extremely gene-rich, consistent with a cytogenetic Giemsa light band. Genes known to lie in this interval include ZNF21, ZNF41, ZNF81, ELK1, and the (PFC-SYN1-TIMP1-ARAF1) gene cluster in Xp11.23 (Nelson et al. 1995) and several CpG islands have been identified that correspond to as yet unknown genes (Coleman et al. 1994). None of the known genes would appear to be strong candidates for $R P 2$ on considering the etiology of the disease, although the recent discovery that mutations in the TIMP3 gene cause Sorsby's fundus dystrophy (Weber et al. 1994), a macular degeneration, has led us to investigate TIMP1 for a causal role in RP2 (A.J. Hardcastle, D.L. Thiselton, M. Nayudu, R.M. Hampson, and S.S. Bhattacharya, in prep.). Recently, other genes have recently been mapped close to UBE1 in Xp11.3: PCTK1, DXS8237E, and ZNF157 (Nelson et al. 1995; Carrel et al. 1996). A UBE1-associated microsatellite, DXS7124 (Coleman et al. 1996), has been positioned proximal to DXS8083 by genetic analysis of a mini "meiotic breakpoint panel" (Gerken et al. 1995) comprising defined recombinants from XLRP families in our laboratory, and therefore falls within the $R P 2$ critical region (data not shown). Unfortunately, DXS7124 is not informative in family F72, therefore possible involvement of these genes in $R P 2$ remains open and is being addressed.

In addition to the meiotic breakpoint panel, we are currently employing a variety of resources to physically map and order genes and markers in the RP2 critical interval flanked by DXS6616 and DXS8083. This combination of genetic and physical mapping methods will enable us to further define the location of the defective gene.

\section{METHODS}

\section{Subjects and Samples}

Two families are presented: family NRP from the USA, comprising four generations with DNA for nine affected males and eight obligate carrier females, and family F72 from Belgium, comprising three generations with DNA for 


\section{GENETIC AND PHYSICAL MAPPING OF THE RP2 LOCUS}

four affected males and two obligate carrier females. A diagnosis of XLRP was based on detailed family history and comprehensive ophthalmological tests including fundus examination, visual field assessment, fluorescein angiography, and electroretinogram (ERG) measurements. DNA extraction from peripheral whole blood was performed using the Nucleon II kit (Scotlab).

\section{Detection of Microsatellite Polymorphisms}

The forward primer for each microsatellite was end-labeled with $\left[\gamma_{-}{ }^{32} \mathrm{P}\right] \mathrm{ATP}$ by incubating the primer at $37^{\circ} \mathrm{C}$ for 45 min with T4 polynucleotide kinase (New England Biolabs). The dinucleotide repeats were then amplified from $100 \mathrm{ng}$ of genomic DNA as described previously (Thiselton et al. 1995). Alleles were detected by electrophoresing the PCR products on $6 \%$ denaturing polyacrylamide gels (Promega), followed by exposure to X-ray film. Specific primer details and PCR conditions for each microsatellite can be obtained from GDB (1995).

\section{Haplotype Analysis}

Nineteen microsatellite markers spanning $\sim 25 \mathrm{cM}$ from Xp21.1 to Xp11.22 (Fain et al. 1995; Thiselton et al. 1995) were used to generate haplotypes for all sampled individuals. From Xp21.1 to Xp11.22 the order of markers is known: CYBB-DXS1110-DXS556-DXS574-DXS977DXS228-DXS7-MAOB-DXS8080 (afmc012zc1)-DXS8083 (afmc024xc5)-DXS1003-DXS1055-SYN1-DXS426DXS1367-DXS6616-DXS6941-DXS1126-DXS573 (Nelson et al. 1995; Dib et al. 1996). Haplotypes were constructed assuming the minimal number of recombination events.

\section{Construction of a YAC Contig Spanning the RP2 Proximal Boundary in Xp11.23}

\section{Sources of Initial STSs and ESTS}

Details of STSs corresponding to genetic markers (SYN1, PFC, DXS426, DXS1367, DXS6616, DXS6941, DXS722, DXS1126, and DXS1240) and expressed sequences TIMP-1, DXS1004E (ZNF41), and DXS1011E may be obtained from GDB (1995). Primer pairs for microsatellite DXS6941 were kindly provided by A. Meindl (Kinderpoliklinik der Universitat Munchen, Germany). Published sequence information for other genes assigned to the region was used to design EST markers from the $3^{\prime}$ untranslated regions (GATA1, MG21, MG44, MG61, and MG81) and these are described in Table 1. STSs for genes ELK1 and ZNF81 were as reported previously (Coleman et al. 1994; Knight et al. 1994).

\section{Identification and Initial Characterization of YACs}

YACs were identified for a STS or EST marker by PCR-based screening of hierarchical pools of clones from the ICI $4 \mathrm{X}$ YAC library (Anand et al. 1990). Intact DNA from each positive clone was prepared in agarose plugs and analysed by PCR to verify STS/EST content, and by pulsed-field gel electrophoresis (PFGE) (CHEF DRII; Bio-Rad) to assess the size and purity of the YACs present. PFGE conditions were run time $17-22 \mathrm{hr}, 5 \mathrm{~V} / \mathrm{cm}$, with a pulse time ramped from $60-90 \mathrm{sec}$ in $0.5 \times \mathrm{TBE}$ at $14^{\circ} \mathrm{C}$. YAC sizes were estimated by comparison with yeast chromosome size standards (Bio-Rad) on 1\% agarose gels by visual inspection after staining the gel with ethidium bromide. If no distinct YAC was visible, Hybond N+ (Amersham) blots were prepared from acid-nicked gels by Southern transfer (Sambrook et al. 1989) and hybridized at $65^{\circ} \mathrm{C}$ overnight with $\left[\alpha-{ }^{32} \mathrm{P}\right] \mathrm{CTP}-\mathrm{labeled}$ total human DNA. The contig was supplemented with YACs for markers SYN1 and 2bC6 (DXS226) from the ICRF YAC library (Larin et al. 1991) through the ICRF Reference Library Database.

\section{Creation of YAC Insert-end STSs}

YAC insert ends were isolated by two methods: ALU- vector PCR using human-specific ALU primers ALE1 (5'GCCTCCCAAAGTGCTGGGATTACAG-3') or ALE3 ( 5'CCAT/CTGCACTCCAGCCTGGG-3') and primers specific for the left and right arms of the pYAC4 vector (LA 5'CACCCGTTCTCGGAGCACTGTCCGACCGC-3'; RA 5'ATATAGGCGCCAGCAACCGCACCTGTGGC-3'), or Vectorette PCR (Riley et al. 1990), using restriction enzymes $P v u I I, D r a I$, and EcoRV with 6-bp recognition sequences, which were found generally to yield large insert terminal PCR products. PCR products were purified and sequenced directly using an internal Vectorette unit primer or pYAC4 primer (LA 5'-GTTGGTTTAAGGCGCAAG-3'; RA 5' GTCGAACGCCCGATCTCAA-3'). End-fragment sequences were subjected to FASTA data-base identity searches before PCR primer design. The new STSs developed from YAC insert ends were tested against a pair of somatic cell hybrids containing portions of the $\mathrm{X}$ chromosome as their only human component; Kag 2.3 (Xp21.1Xqter) and Sin 176 (deleted for Xp22.1-Xp11.22; Lafreniere et al. 1991) to provide an initial indication that they derived from proximal $\mathrm{Xp}$.

\section{YAC Contig Construction by STS-content Mapping}

The YAC contig was constructed by determining the STS content of each YAC and therefore establishing overlaps between clones. The orientation of the contig was deduced from the known order of genetic markers mapping to the contig, that is, Xpter-PFC-DXS426-DXS722-DXS1126Xcen (Nelson et al. 1995).

\section{ACKNOWLEDGMENTS}

We gratefully acknowledge the Human Genome Mapping Project Resource Centre for invaluable YAC and primer provision, and thank the Ulverscroft Foundation (D.L.T.) and Wellcome Trust (A.J.H.; grant no. 042019/Z/94/Z) WRE/MB/JAT) for their support. Sample collection and diagnosis for family NRP was supported by the National Society to Prevent Blindness awarded in memory of Silas Adelsheim (B.K.S.).

The publication costs of this article were defrayed in part by payment of page charges. This article must there- 


\section{THISELTON ET AL.}

fore be hereby marked "advertisement" in accordance with 18 USC section 1734 solely to indicate this fact.

\section{REFERENCES}

Aldred, M.A., K.L. Dry, D.M. Sharp, D.B. Van Dorp, J. Brown, L.J. Hardwick, D.H. Lester, F.E. Pryde, P.W. Teague, M. Jay, A.C. Bird, B. Jay, and A.F. Wright. 1992. Linkage analysis in $\mathrm{X}$-linked congenital stationary night blindness. Genomics 14: 99-104.

Aldred, M.A., P.W. Teague, M. Jay, S.A. Bundey, R.M. Redmond, B. Jay, A.C. Bird, S.S. Bhattacharya, and A.F. Wright. 1994. Retinitis pigmentosa families showing apparent $X$ linked inheritance but unlinked to the RP2 or RP3 loci. J. Med. Genet. 31: 848-852.

Anand, R., J.H. Riley, R. Butler, J.C. Smith, and A.F. Markham. 1990. A 3.5 genome equivalent multi access YAC library: Construction, characterisation, screening and storage. Nucleic Acids Res. 18: 1951-1956.

Arden, G.B., R.M. Carter, C.R. Hogg, D.J. Powell, W.J. Ernst, G.M. Clover, A.L. Lyness, and M.P. Quinlan. 1983. A modified ERG technique and the results obtained in $\mathrm{X}$-linked retinitis pigmentosa. Br. J. Ophthalmol. 67: 419-30.

Bech-Hansen, N.T., B.J. Moore, and W.G. Pearce. 1992. Mapping of locus for X-linked congenital stationary night blindness (CSNB1) proximal to DXS7. Genomics 12: 409-411.

Bergen, A.A.B., L.I. Van der Born, E.J.M. Schuurman, A.J.L.G. Pinckers, E.M. Bleeker-Wagemakers, G.J.B. van Ommen, and L.A. Sandkuijl. 1995. Mulitpoint linkage analysis and homogeneity tests in 15 Dutch X-linked retinitis pigmentosa families. Ophthalmic Genet. 16: $63-70$.

Berger, W., G. van Duijnhoven, A. Pinckers, A. Smits, H. Hilger Ropers, and F. Cremers. 1995. Linkage analysis in a Dutch family with $\mathrm{X}$-linked recessive congenital stationary night blindness (XL-CSNB). Hum. Genet. 95: $67-70$.

Bhattacharya, S.S., A.F. Wright, J.F. Clayton, W.H. Price, C.I. Phillips, C.M.E. McKeown, M. Jay, A.C. Bird, P.L. Pearson, E.M. Southern, and H.J. Evans. 1984. Close linkage between X-linked retinitis pigmentosa and a restriction fragment length polymorphism identified by recombinant DNA probe L1.28. Nature 309: 253-255.

Bird, A.C. 1975. X-linked retinitis pigmentosa. $\mathrm{Br}$. J. Ophthalmol. 59: 177-199.

Boycott, K.M., G.R. Halley, D. Schlessinger, and N.T. Bech-hansen. 1996. A 2-megabase physical contig incorporating 43 DNA markers on the human $\mathrm{X}$ chromosome at p11.23-p11.22 from ZNF21 to DXS255. Genomics 33: 488-497.

Carrel, L., C.M. Clemson, J.M. Dunn, A.P. Miller, P.A.
Hunt, J.B. Lawrence, and H.F. Willard. 1996. X inactivation analysis and DNA methylation studies of the ubiquitin activating enzyme E1 and PCTAIRE-1 genes in human and mouse. Hum. Mol. Genet. 5: $391-401$.

Chand, A., J. Clark, C.S. Cooper, and I.W. Craig. 1995. Long-range organisation of reiterated sequences, including the SSX1 CDNA, at the OATL1 cluster in Xp11.23. Genomics 30: $545-552$.

Coleman, M.P., A.H. Nemeth, L. Campbell, C.P. Raut, J. Weissenbach, and K.E. Davies. 1994. A 1.8 Mb YAC contig in Xp11.23: Identification of $\mathrm{CpG}$ islands and physical mapping of CA repeats in a region of high gene density. Genomics 21: 337-343.

Coleman, M.P., H.J. Ambrose, L. Carrel, A.H. Nemeth, H.F. Willard, and K.E. Davies. 1996. A novel gene, DXS8237E, lies within 20kb upstream of UBE1 in Xp11.23 and has a different X-inactivation status. Genomics 31: 135-138.

Dib, C., S. Faure, C. Fizames, D. Samson, N. Drouot, A. Vignal, P. Millasseau, S. Marc, J. Hazan, E. Seboun, M. Lathrop, G. Gyapay, J. Morissette, and J. Weissenbach. 1996. A comprehensive map of the human genome based on 5264 microsatellites. Nature 380: 152-154.

Dryja, T.P. and T. Li. 1995. Molecular genetics of retinitis pigmentosa. Hum. Mol. Genet. 4: 1739-1743.

Dryja, T.P., E.L. Berson, V.R. Rao, and D.D. Oprian. 1993. Heterozygous missense mutation in the rhodopsin gene as a cause of congenital stationary night blindness. Nature Genet. 4: 280-283.

Fain, P.R., E.N. Kort, P.F. Chance, K. Nguyen, D.F. Redd, M. J. Econs, and D.F. Barker. 1995. A 2D crossover-based map of the human $\mathrm{X}$ chromosome as a model for map integration. Nature Genet. 9: 261-266.

Fisher, S.E., E. Hatchwell, A. Chand, N. Ockenden, A.P. Monaco, and I.W. Craig. 1995. Construction of two YAC contigs in human Xp11.23-p11.22, one encompassing the loci OATL1, GATA, TFE3 and SYP, the other linking DXS255 to DXS146. Genomics 29: 496-502.

Friedrich, U., M. Warburg, T.A. Kruse, and S. Andreasson. 1992. X-linked retinitis pigmentosa: New map studies of XLRP2, and a possible human centromere effect. Hum. Genet. 88: 683-687.

Gal, A., U. Orth, W. Baehr, E. Schwinger, and T. Rosenberg. 1994. Heterozygous missense mutation in the rod cGMP phosphodiesterase $\beta$-subunit gene in autosomal dominant stationary night blindness. Nature Genet. 7: 64-68.

GDB Human Genome Database. 1995. Online database 1900-. Updated daily (cited October 1995). John Hopkins University, Baltimore. Available from Internet: URL: http://gdbwww.gdb.org/gdb/browser/docs/topq.html 


\section{GENETIC AND PHYSICAL MAPPING OF THE RP2 LOCUS}

Geraghty, M.T., L.C. Brody, L.S. Martin, M. Marble, W. Kearns, P. Pearson, A.P. Monaco, H. Lehrach, and D. Valle. 1993. The isolation of cDNAS from OATL1 at Xp11.2 using a 480kb YAC. Genomics 16: 440-446.

Gerken, S.C., H. Albertson, T. Elsner, L. Ballard, P. Holik, E. Lawrence, M. Moore, X. Zhao, and R. White. 1995. A strategy for constructing high-resolution genetic maps of the human genome: A genetic map of chromosome 17p, ordered with meiotic breakpoint mapping panels. Am. J. Hum. Genet. 56: 484-499.

Hagemann, T., R. Surosky, A.P. Monaco, H. Lehrach, F.S. Rosen, and S. Kwan. 1994. Physical mapping in a YAC contig of 11 markers on the human $X$ chromosome in Xp11.23. Genomics 21: 262-265.

Heckenlively, J. 1983. The hereditary and choroidal degenerations. In Principles and practice of medical genetics (ed. A.E.H. Emery and D.L. Rimioin), Vol. 1, pp. 522-538. Churchill Livingston, Edinburgh, UK.

Hong, H., R.E. Ferrell, and M.B. Gorin. 1994. Clinical diversity and chromosomal localisation of $\mathrm{X}$-linked cone dystrophy (COD1). Am. J. Hum. Genet. 55: 1173-1181.

Jay, M. 1982. On the heredity of X-linked retinitis pigmentosa. Br. J. Ophthalmol. 66: 405-416.

Knight, J.C., G. Grimaldi, H. Thiesen, N.T. Bech-hansen, C.D.M. Fletcher, and M. Coleman. 1994. Clustered organisation of Kruppel zinc-finger genes at Xp11.23 flanking a translocation breakpoint at OATL1: A physical map with locus assignments for ZNF21, ZNF41, ZNF81, and ELK1. Genomics 21: 180-187.

Kwan, S., T.L. Hagemann, R.M. Blaese, and F.S. Rosen. 1995. A high-resolution map of genes, microsatellite markers and new dinucleotide repeats from UBE1 to the GATA locus in the region Xp11.23. Genomics 29: $247-252$.

Lafreniere, R.G., C.J. Brown, V.E. Powers, L. Carrel, K.E. Davies, D.F. Barker, and H.F. Willard. 1991. Physical mapping of 60 markers in the p21.1 $\rightarrow$ q21.3 region of the human X chromosome. Genomics 11: 352-363.

Larin, Z., A.P. Monaco, and H. Lehrach. 1991. Yeast artificial chromosome libraries containing large inserts from mouse and human DNA. Proc. Natl. Acad. Sci. 88: $4123-4127$.

McGuire, R.E., L.S. Sullivan, S.H. Blanton, M.W. Church, J.R. Heckenlively, and S.P. Daiger. 1995. X-linked dominant cone-rod degeneration: Linkage mapping of a new locus for retinitis pigmentosa (RP15) to Xp22.13-p22.11. Am. J. Hum. Genet. 57: 87-94.

Meire, F.M., A.A.B. Bergen, A. De Rouck, M. Leys, and J.W. Delleman. 1994. X linked progressive cone dystrophy: Localisation of the gene locus to Xp21-Xp11 by linkage analysis. Br. J. Ophthalmol. 78: 103-108.

Meindl, A., K. Dry, K. Hermann, F. Manson, A.
Ciccodicola, A. Edgar, M.R.S. Carvalho, H. Achatz, H. Hellebrand, A. Lennon, C. Migliaccio, K. Porter, E. Zrenner, A. Bird, M. Jay, B. Lorenz, B. Wittwer, M. d'Urso, T. Meitinger, and A. Wright. 1996. A gene ( $R P G R$ ) with homology to the RCC1 family of guanine nucleotide exchange factors is mutated in X-linked retinitis pigmentosa (RP3). Nature Genet. 13: 36-42.

Musarella, M.A., L. Anson-Cartwright, S.M. Leal, L.D. Gilbert, R.G. Worton, G.A. Fishman, and J. Ott. 1990. Multipoint linkage analysis and heterogeneity testing in $20 \mathrm{X}$-linked retinitis pigmentosa families. Genomics 8: $286-296$.

Nelson, D.L., A. Ballabio, F. Cremers, A.P. Monaco, and D. Schlessinger. 1995. Report of the sixth international workshop on X chromosome mapping. Cytogenet. Cell Genet. 71: 308-336.

Ott, J., S. Bhattacharya, J.D. Chen, M.J. Denton, J. Donald, C. Dubay, G.J. Farrar, G.A. Fishman, D. Frey, A. Gal, P. Humphries, B. Jay, M. Jay, M. Litt, M. Machler, M. Musarella, M. Neugebauer, R. Nussbaum, J.D. Terwilliger, R.G. Weleber, B. Wirth, F. Wong, R.G. Worton, and A.F. Wright. 1990. Localising multiple X chromosome-linked retinitis pigmentosa loci using multiple homogeneity tests. Proc. Natl. Acad. Sci. 87: 701-704.

Rao, V.K., G.B. Cohen, and D.D. Oprian. 1994. Rhodopsin mutation G90D and a molecular mechanism for congenital stationary night blindness. Nature 367: 639-642.

Riley, J., R. Butler, D. Ogilvie, R. Finniear, D. Jenner, S. Powell, R. Anand, J.C. Smith, and A.F. Markham. 1990. A novel, rapid method for the isolation of terminal sequences from yeast artificial chromosome (YAC) clones. Nucleic Acids Res. 18: 2887-2890.

Roux, A.F., J. Rommens, C. McDowell, L. Anson-Cartwright, S. Bell, K. Schappert, G.A. Fishman, and M. Musarella. 1994. Identification of a gene from Xp21 with similarity to the tctex-1 gene of the murine $t$ complex. Hum. Mol. Genet. 3: 257-263.

Sambrook, J., E.F. Fritsch, and T. Maniatis. 1989. Molecular cloning: A laboratory manual. Cold Spring Harbor Laboratory Press, Cold Spring Harbor, NY.

Teague, P.W., M.A. Aldred, M. Jay, M. Dempster, C. Harrison, A.D. Carothers, L.J. Hardwick, H.J. Evans, L. Strain, D.J.H. Brock, S. Bundey, B. Jay, A.C. Bird, S.S. Bhattacharya, and A.F. Wright. 1994. Heterogeneity analysis in $40 \mathrm{X}$-linked retinitis pigmentosa families. Am. J. Hum. Genet. 55: 105-111.

Thiselton, D.L., S. Lindsay, S. Kamakari, A.J. Hardcastle, P. Roustan, and S.S. Bhattacharya. 1995. Genetic and physical mapping of five novel microsatellite markers on human Xp21.1-p11.22. Genomics 25: 279-281.

Weber, B.H.F., G. Vogt, R.C. Pruett, H. Stohr, and U. Felbor. 1994. Mutations in the tissue inhibitor of 


\section{THISELTON ET AL.}

metalloproteinases-3 (TIMP3) in patients with Sorsby's fundus dystrophy. Nature Genet. 8: 352-356.

Wright, A.F., S.S. Bhattacharya, M.A. Aldred, M. Jay, A.D. Carothers, N.S.T. Thomas, A.C. Bird, B. Jay, and H.J. Evans. 1991. Genetic localisation of the RP2 type of X linked retinitis pigmentosa in a large kindred. J. Med. Genet. 28: $453-457$.

Received July 2, 1996; accepted in revised form September 6, 1996. 


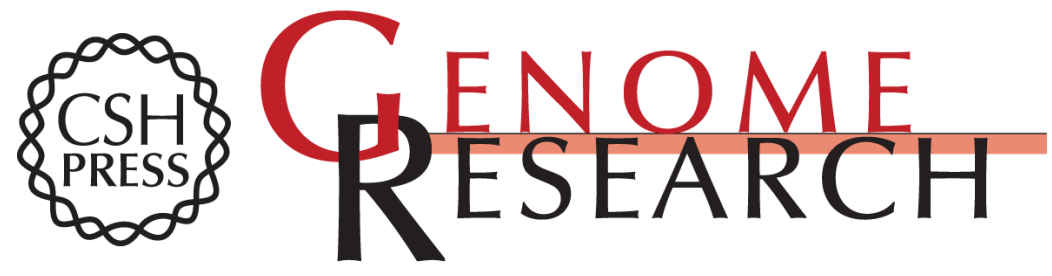

\section{Mapping the RP2 locus for X-linked retinitis pigmentosa on proximal Xp: a genetically defined 5-cM critical region and exclusion of candidate genes by physical mapping.}

D L Thiselton, R M Hampson, M Nayudu, et al.

Genome Res. 1996 6: 1093-1102

Access the most recent version at doi:10.1101/gr.6.11.1093

References This article cites 43 articles, 8 of which can be accessed free at: http://genome.cshlp.org/content/6/11/1093.full.html\#ref-list-1

License

Email Alerting

Receive free email alerts when new articles cite this article - sign up in the box at the Service top right corner of the article or click here.

\section{Affordable, Accurate Sequencing.}

